\title{
Low lung function and the risk of incident chronic kidney disease in the Malmö Preventive Project cohort
}

\author{
Suneela Zaigham ${ }^{1 *}$, Anders Christensson ${ }^{1,2}$, Per Wollmer $^{3}$ and Gunnar Engström ${ }^{1}$
}

\begin{abstract}
Background: Although the prevalence of kidney disease is higher in those with reduced lung function, the longitudinal relationship between low lung function and future risk of chronic kidney disease (CKD) has not been widely explored.

Methods: Baseline lung function was assessed in 20,700 men and 7325 women from 1974 to 1992. Mean age was $43.4( \pm 6.6)$ and $47.5( \pm 7.9)$ for men and women respectively. Sex-specific quartiles of $F E V_{1}$ and FVC (L) were created (Q4: highest, reference) and the cohort was also divided by the $\mathrm{FEV}_{1} / \mathrm{FVC}$ ratio $(\geq$ or $<0.70)$. Cox proportional hazards regression was used to determine the risk of incident CKD events (inpatient or outpatient hospital diagnosis of (KD) in relation to baseline lung function after adjustment for various confounding factors.

Results: Over 41 years of follow-up there were 710 and 165 incident CKD events (main diagnosis) in men and women respectively. Low FEV 1 was strongly associated with future risk of CKD in men (Q1 vs Q4 adjusted HR: 1.46 (Cl:1.14-1.89), p-trend 0.002). Similar findings were observed for FVC in men (1.51 (Cl:1.16-1.95), p-trend 0.001). The adjusted risks were not found to be significant in women, for either $\mathrm{FEV}_{1}$ or $\mathrm{FVC}$. FEV $1 / F V C<0.70$ was not associated with increased incidence of CKD in men or women.

Conclusion: Low FEV 1 and FVC levels at baseline are a risk factor for the development of future incident CKD in men. Monitoring kidney function in those with reduced vital capacity in early life could help with identifying those at increased risk of future CKD.
\end{abstract}

Keywords: Lung function, Spirometry, Incidence, Cohort, Chronic kidney disease

\section{Background}

Chronic kidney disease (CKD) has become an important public health issue [1]. It encompasses substantial morbidity and mortality globally along with important economic implications to health systems $[1,2]$. It is an independent risk factor for cardiovascular disease (CVD), which in turn is a major cause of the morbidity and mortality associated with CKD [2]. It has been

\footnotetext{
* Correspondence: suneela.zaigham@med.lu.se

'Department of Clinical Sciences Malmö, Lund University, CRC 60:13, Jan Waldenströms gata 35, S-20502 Malmö, Sweden

Full list of author information is available at the end of the article
}

found that even in early stage kidney disease, the prevalence of adverse clinical outcomes is increased [1] and as such, the early identification of risk factors for CKD is key. Some of the important risk factors for CKD include diabetes mellitus (DM), smoking, hypertension and low birth weight [2-4], all of which are factors also known to be associated with low lung function [5-15].

Additionally, low lung function early in life is known to be a powerful risk factor for future CVD and coronary events $(\mathrm{CE})$ and mortality associated with both CVD and CE [16-24]. Establishing the relationship between low lung function early on in life and future CKD could

(c) The Author(s). 2020 Open Access This article is licensed under a Creative Commons Attribution 4.0 International License, which permits use, sharing, adaptation, distribution and reproduction in any medium or format, as long as you give appropriate credit to the original author(s) and the source, provide a link to the Creative Commons licence, and indicate if changes were made. The images or other third party material in this article are included in the article's Creative Commons licence, unless indicated otherwise in a credit line to the material. If material is not included in the article's Creative Commons licence and your intended use is not permitted by statutory regulation or exceeds the permitted use, you will need to obtain permission directly from the copyright holder. To view a copy of this licence, visit http://creativecommons.org/licenses/by/4.0/. The Creative Commons Public Domain Dedication waiver (http://creativecommons.org/publicdomain/zero/1.0/) applies to the data made available in this article, unless otherwise stated in a credit line to the data. 
therefore provide an additional strategy to help identify and reduce the risk of at-risk individuals and reduce the overall morbidity and mortality associated with CKD.

Although there has been some cross-sectional research assessing the relationship between low lung function and CKD [25-29], we are aware of few studies assessing the role of lung function in the prediction of incident kidney disease [30,31], which have found low lung function to be independently associated with CKD progression.

We aimed to use the Malmö Preventive Project (MPP) cohort to assess the longitudinal relationship between low lung function early in life and the future risk of CKD. We have previously used this cohort to show that poor lung function precedes and significantly predicts the development of DM [5]. If the findings of the prospective study by Sumida et al. [30] can be replicated in the present cohort, it will inevitably add further evidence into the rationale for monitoring kidney function in those with low lung function early in life.

\section{Methods}

\section{Study population}

The study population consisted of subjects from the MPP cohort. Screening activities were carried out between 1974 and 1992 in 33,346 subjects (22,444 men and 10,902 women). The attendance rate was over $70 \%$. The aim of the MPP was to screen middle-aged individuals with an aim to offer preventative treatment to any identified high-risk individuals during the screening. Complete birth cohorts for 1921-1949 were invited for a physical examination, laboratory tests, spirometry and a self-administered questionnaire. During 1974-82 men were mostly screened and during 1982-92 women were mostly screened. The screening program was approved by the Health Service Authority of Malmö. Linkage with the national cause of death and patient registers was approved by the Regional Ethics Committee at Lund.

Subjects with prevalent CKD (register recorded diagnosis before the start of the study $(n=18)$, or a baseline estimated glomerular filtration rate $($ eGFR $)<60 \mathrm{~mL} / \mathrm{min} /$ $\left.1.73 \mathrm{~m}^{2}(n=621)\right)$ were excluded at baseline. The CKD classification in this study is based on eGFR alone in accordance with the 2012 KDIGO guidelines, since data on urine albumin is not available from the MPP cohort. Furthermore, it is based on only one eGFR measurement and not two with at least 3 months between (Stage 1 (normal kidney function, GFR $\geq 90 \mathrm{~mL} / \mathrm{min} / 1.73 \mathrm{~m}^{2}$ ), stage 2 (mild reduction, GFR 60-89), stage 3a (mild-moderate reduction, GFR 45-59), stage 3b (moderate to severe reduction, GFR 30-44), stage 4 (severe reduction, GFR 15-29), stage 5 (established kidney failure, GFR < 15)). CKD is defined as stage 3 or higher [32].

Spirometry was performed in birth cohorts during most but not all screening time periods $(94 \%$ of men and $71 \%$ of women underwent spirometry), however individuals were not selected based on symptoms or disease. Those with missing information on forced vital capacity (FVC) or forced expiratory volume in $1 \mathrm{~s}\left(\mathrm{FEV}_{1}\right)$ were then excluded $(n=4410)$. Subjects with missing information on baseline eGFR $(n=87)$ and those with an outlying value of eGFR $(n=1)$ were excluded. Subjects with missing information on other covariates were also excluded $(n=121)$ or with no follow-up time recorded $(\mathrm{n}=1)$. Those with an erythrocyte sedimentation rate (ESR) $\geq 50 \mathrm{~mm} / \mathrm{h}$ were also excluded as this could indicate any specific inflammatory lung pathology $(n=62)$. The final study population consisted of 28,025 subjects (20,700 men and 7325 women).

\section{Baseline examinations Physical examination}

Spirometry was carried out by trained nursing staff using a Spirotron apparatus (Drägerwerk AG, Lübeck, Germany). One acceptable manoeuvre was required. A fixed stadiometer was used to measure height $(\mathrm{m})$ and a balance beam scale to measure weight $(\mathrm{kg})$. Blood pressure $(\mathrm{mmHg})$ was measured after a 10-min rest in the supine position (two measurements taken and mean value recorded). eGFR was calculated using CKD-EPI 2009 (CKD Epidemiology Collaboration) creatinine equation [33].

\section{Laboratory assessments}

Blood samples were taken after an overnight fast and were analysed at the Department of Clinical Chemistry, Malmö University Hospital using routine methods (serum total cholesterol and whole blood glucose). The Westergren method was used to determine ESR. During the study period, creatinine was measured with the Jaffe method using a Technicon Auto Analyzer II at the Department of Clinical Chemistry at the University Hospital in Malmö. This method was not calibrated to isotope dilution mass spectrometry (IDMS) traceable values. The reference range was $80-115 \mu \mathrm{mol} / \mathrm{L}$ for men and $60-100 \mu \mathrm{mol} / \mathrm{L}$ for women.

\section{Questionnaire}

A questionnaire was used to establish smoking habits, prevalent diabetes or CVD, antihypertensive medication use and physical activity. Subjects were then classified as never, former or current smokers based on their responses. In men, physical activity was assessed using the following question: "Are you mostly engaged in sedentary activity in your spare time?" and in women the following two questions were used: (1) "Are you engaged in physical activity (e.g. swimming, gymnastics, badminton, tennis, folk dance, running etc.) 1-2 hours per week?" or (2) Do you usually get to do light exercise like walking or cycling (or other activities with similar effort) on a regular 
weekly basis?". Low socioeconomic status was defined as Statistics Sweden socioeconomic index (SEI) group 1136 (unskilled, or skilled manual workers, or low level non-manual workers).

Prevalent CVD was assessed using answers related to the presence of symptoms and signs of CVD on questionnaire or a hospital diagnosis of myocardial infarction or stroke. Prevalent DM was assessed using fasting whole blood glucose $\geq 6.1 \mathrm{mmol} / \mathrm{L}$ (=plasma glucose $\geq 7.0 \mathrm{mmol} /$ L), self-reported diabetes or diabetes medication according to questionnaire or any prior diagnosis of diabetes in diabetes registers.

\section{Endpoint ascertainment}

CKD was defined using International classification of diseases (ICD) 8, 9 and 10 codes: (ICD-8: codes 582.00 and 582.09, ICD-9: code 585 and ICD-10 codes N18. Additionally any diagnosis of acute kidney disease (AKD) that also subsequently led to a diagnosis of CKD was also defined as CKD (ICD-8 code 583.99, ICD-9 code 586 or ICD-10 code N19 with any of the codes $582.00,582.09,585$ or N18 in the same individual at a later time point). The endpoints were retrieved from the Swedish inpatient register and the hospital-based outpatient register. The inpatient register has been operating in south of Sweden since 1970 and became nationwide in 1987. The outpatient register has been operating since 2001. A validation study was performed of the diagnosis of CKD in the inpatient and hospital-based outpatient registers, by two experienced nephrologists. The hospital records were reviewed and validated according to the criteria [34]. The validation showed that the diagnosis of CKD in these registers was correct or had high probability in $94 \%$ of the cases [35].

The two endpoints included: (1) Incident CKD - main diagnosis (main diagnosis on either the inpatient register or outpatient register) and (2) Incident CKD (main diagnosis or one of the first three secondary diagnoses). All subjects were followed from baseline examination to the first main CKD event (endpoint 1) or first main or secondary CKD event (endpoint 2), death, emigration or last follow-up date 31st December 2016, whichever came first.

\section{Statistical analysis}

All statistical analyses were carried out using SPSS (IBM Corp. Released 2016. IBM SPSS Statistics for Windows, Version 24.0. Armonk, NY: IBM Corp). Sex- specific quartiles of $\mathrm{FEV}_{1}$ and $\mathrm{FVC}(\mathrm{L})$ were created (Q4 reference, Q1 = low lung function). Variables with a positively skewed distribution were log-transformed (ESR). To compare baseline characteristics between subjects in quartiles of $\mathrm{FEV}_{1}$ or FVC, one-way analysis of variance (ANOVA) and Pearson's chi-squared test were used. Cox proportional hazards regression was used to assess the incidence of CKD according to quartiles of $\mathrm{FEV}_{1}$ and FVC. Adjustments were made for potential confounding factors including age, baseline eGFR, height, body mass index (BMI), smoking status, cholesterol, history of CVD, history of diabetes, systolic blood pressure (BP), physical activity, social class, ESR (log transformed), BP medication and screening year. The proportional hazards assumptions were tested using time-dependent covariate analysis in the adjusted models in SPSS and Kaplan Meier curves.

As the creatinine values were analysed before IDMS was introduced, the serum creatinine values and eGFR used could have resulted in slightly different estimates of eGFR than otherwise would have been if IDMS traceable creatinine values were used. To assess if this would have affected any results, we also peformed a sensitivity analyses by widening the baseline exclusion criteria to eGFR $<70 \mathrm{~mL} / \mathrm{min} / 1.73 \mathrm{~m}^{2}$ to ensure that we did not include any potential cases at baseline by using an older creatinine assay.

\section{Results \\ Baseline characteristics}

Baseline characteristics are presented in Tables 1 and 2 for $\mathrm{FEV}_{1}$ and in Supplement Tables 1 and 2 for FVC. As lung function decreased (Q1 vs Q4), age, BMI, BP and cholesterol increased, along with the proportion of subjects who were current smokers, physically inactive, on $\mathrm{BP}$ medication or had prevalent conditions such as CVD or DM (p-trend $<0.001)$. Height and eGFR decreased as lung function decreased ( $\mathrm{p}$-trend $<0.001$ ). As lung function decreased, the proportion of subjects in low skilled employment increased and the proportion of those in high skilled employment decreased in Q1 vs Q4 (ptrend $<0.001$ ). This trend was seen for quartiles of both $\mathrm{FEV}_{1}$ and $\mathrm{FVC}$ and in men and women.

\section{Incidence of CKD}

Mean follow-up time was 31 years for men and 30 years for women. There were 710 incident CKD events where CKD was the main diagnosis and 1021 incident CKD events where CKD was either the main or a secondary diagnosis in men. For women these were 165 and 237 events respectively. The hazard ratios (HR) of incident CKD events by quartiles of $\mathrm{FEV}_{1}$ for men and women are shown in Tables 3 and 4, respectively. In men, there was an approximately $46 \%$ increase in the adjusted risk of incident CKD as the main diagnosis in $\mathrm{Q} 1$ of $^{\mathrm{FEV}} \mathrm{V}_{1}$ vs Q4 (reference) (p-trend: 0.002) and a 43\% increase in the adjusted risk of incident CKD as the main or secondary diagnosis (p-trend: <0.001). For quartiles of FVC in men, there was a $51 \%$ increase in the adjusted risk of incident CKD as the main diagnosis in Q1 vs Q4 (ptrend: 0.001 ), and $45 \%$ increase in the adjusted risk of 


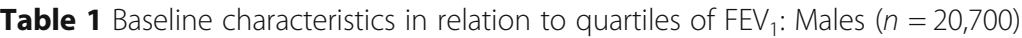

\begin{tabular}{|c|c|c|c|c|c|c|}
\hline & Overall & Q4 & Q3 & Q2 & Q1 & $\boldsymbol{P}$ value for trend \\
\hline $\mathrm{FEV}_{1}(\mathrm{~L})$ & $3.52( \pm 0.77)$ & $4.51( \pm 0.42)$ & $3.79( \pm 0.14)$ & $3.31( \pm 0.14)$ & $2.58( \pm 0.44)$ & - \\
\hline Number (n) & 20,700 & 4813 & 5176 & 5388 & 5323 & - \\
\hline Age (years) & $43.4( \pm 6.6)$ & $40.0( \pm 6.0)$ & $42.2( \pm 6.0)$ & $44.1( \pm 6.1)$ & $46.8( \pm 6.4)$ & $<0.001$ \\
\hline Height (m) & $1.77( \pm 0.07)$ & $1.81( \pm 0.06)$ & $1.78( \pm 0.06)$ & $1.76( \pm 0.06)$ & $1.74( \pm 0.06)$ & $<0.001$ \\
\hline BMI $\left(\mathrm{kg} / \mathrm{m}^{2}\right)$ & $24.6( \pm 3.3)$ & $24.0( \pm 2.9)$ & $24.5( \pm 3.1)$ & $24.7( \pm 3.3)$ & $25.2( \pm 3.6)$ & $<0.001$ \\
\hline Baseline eGFR (mL/min/1.73m²) & $88.0( \pm 13.2)$ & $89.4( \pm 13.3)$ & $88.2( \pm 13.0)$ & $87.5( \pm 13.0)$ & $87.1( \pm 13.3)$ & $<0.001$ \\
\hline Current-smokers (\%) & 49.2 & 37.9 & 44.2 & 51.3 & 62.3 & $<0.001$ \\
\hline Physical inactivity (\%) & 52.5 & 44.7 & 50.1 & 54.1 & 60.3 & $<0.001$ \\
\hline Systolic BP (mmHg) & $127( \pm 15)$ & $125( \pm 13)$ & $126( \pm 14)$ & $127( \pm 15)$ & $129( \pm 16)$ & $<0.001$ \\
\hline Anti-hypertensive medication (\%) & 3.7 & 1.9 & 2.8 & 3.4 & 6.5 & $<0.001$ \\
\hline Cholesterol (mmol/L) & $5.59( \pm 1.07)$ & $5.39( \pm 1.02)$ & $5.56( \pm 1.03)$ & $5.66( \pm 1.08)$ & $5.73( \pm 1.10)$ & $<0.001$ \\
\hline History of CVD & 0.9 & 0.3 & 0.5 & 0.9 & 2.0 & $<0.001$ \\
\hline History of diabetes & 3.2 & 2.1 & 2.3 & 3.5 & 4.9 & $<0.001$ \\
\hline Social class (\%) & & & & & & $<0.001$ \\
\hline - Low skilled & 45.0 & 38.4 & 42.2 & 46.5 & 52.2 & \\
\hline - High skilled & 43.6 & 52.1 & 46.9 & 42.0 & 34.2 & \\
\hline - Self-employed & 8.3 & 7.8 & 8.8 & 8.6 & 8.0 & \\
\hline - Other & 3.1 & 1.7 & 2.1 & 2.9 & 5.6 & \\
\hline
\end{tabular}

Q Quartile, FEV 1 Forced expiratory volume in $1 \mathrm{~s}$, eGFR Estimated glomerular filtration rate, BMI Body mass index, BP Blood pressure, CVD Cardiovascular disease. Data consist of mean ( \pm standard deviation) unless otherwise stated. Linear by linear association for chi square tests used for $p$-value for categorical variables, ANOVA test for linearity used for $p$-values of continuous variables

incident CKD as the main or secondary diagnosis in Q1 vs Q4 (p-trend: 0.001) (Supplement Table 3). For women, the risk of incident CKD became nonsignificant in Q1 of FEV 1 and FVC vs the reference after adjustment for confounding factors (Table 4 and Supplement Table 4).

Figures 1 and 2 illustrate the differences in cumulative CKD incidence (main CKD diagnosis events only) for quartiles of $\mathrm{FEV}_{1}$ in men and women respectively. Differences between the quartiles were tested using the logrank test, overall pooled and pairwise comparisons. For men, the $p$-value for overall comparisons using the logrank test was $<0.001$. Pairwise comparisons found a $p$ value of $<0.05$ for Q1 vs Q2, Q1 vs Q3 and Q1 vs Q4. For women, the $\mathrm{p}$-value for overall comparisons using the log-rank test $<0.001$. Pairwise comparisons found a $\mathrm{p}$-value of $p<0.05$ for Q1 vs Q3 and Q1 vs Q4, but not Q1 vs Q2.

Additionally, there was no increase in the adjusted risk of incident CKD events in those with a ratio of $\mathrm{FEV}_{1}$ / $\mathrm{FVC}<0.70$ compared to those with a $\mathrm{FEV}_{1} / \mathrm{FVC} \geq 0.70$ at baseline (Supplement Tables 5 and 6).

\section{Sensitivity analysis}

To ensure that we did not include any potential cases at baseline by using an older creatinine assay, we carried out a sensitivity analysis where we widened the baseline exclusion criteria to exclude those with a eGFR $<70 \mathrm{~mL} /$ $\min / 1.73^{2}$. This resulted in an exclusion of a further 1683 subjects from the original cohort of 20,700 men and a further exclusion of 1173 subjects from the original cohort of 7325 women. The results remained significant in men. The adjusted hazard ratio for incident $\mathrm{CKD}$ as the main diagnosis for Q1 vs Q4 of $\mathrm{FEV}_{1}$ in men was $1.45(1.10-1.90)$ (p-trend 0.005) and for incident CKD as main or secondary diagnosis was 1.57 (1.24-1.98) (p-trend <0.001). The results for women remained non-significant. The adjusted hazard ratio for incident CKD as the main diagnosis for Q1 vs Q4 of $\mathrm{FEV}_{1}$ in women was $1.30(0.67-2.54)$ ( $\mathrm{p}$-trend 0.408) and for incident CKD as main or secondary diagnosis the results again remained non-significant (Q1 vs Q4 (reference): 1.15 (0.67-2.00), p-trend: 0.589).

\section{Discussion}

Although a cross-sectional relationship between low lung function and CKD previously has been found in subjects with chronic obstructive pulmonary disease (COPD) $[25,27,28]$, the longitudinal relationship between low lung function early in life and the future risk of incident CKD has not been as widely established Our study investigates this longitudinal relationship in over 28,000 subjects in the MPP cohort. We have found that low $\mathrm{FEV}_{1}$ and $\mathrm{FVC}$ values at baseline have a strong 
Table 2 Baseline characteristics in relation to quartiles of FEV ${ }_{1}$ : Females $(n=7325)$

\begin{tabular}{|c|c|c|c|c|c|c|}
\hline & Overall & Q4 & Q3 & Q2 & Q1 & $\boldsymbol{P}$ value for trend \\
\hline $\mathrm{FEV}_{1}(\mathrm{~L})$ & $2.63( \pm 0.58)$ & $3.31( \pm 0.33)$ & $2.80( \pm 0.08)$ & $2.46( \pm 0.11)$ & $1.88( \pm 0.33)$ & - \\
\hline Number (n) & 7325 & 2027 & 1629 & 1933 & 1736 & - \\
\hline Age (years) & $47.5( \pm 7.9)$ & $43.7( \pm 8.0)$ & $46.1( \pm 7.9)$ & $48.9( \pm 7.1)$ & $51.7( \pm 5.6)$ & $<0.001$ \\
\hline Height (m) & $1.64( \pm 0.06)$ & $1.67( \pm 0.05)$ & $1.64( \pm 0.05)$ & $1.62( \pm 0.05)$ & $1.61( \pm 0.06)$ & $<0.001$ \\
\hline BMI $\left(\mathrm{kg} / \mathrm{m}^{2}\right)$ & $23.9( \pm 4.0)$ & $23.0( \pm 3.4)$ & $23.6( \pm 3.7)$ & $24.2( \pm 4.1)$ & $24.6( \pm 4.6)$ & $<0.001$ \\
\hline Baseline eGFR (mL/min/1.73m²) & $84.1( \pm 13.6)$ & $85.6( \pm 13.9)$ & $84.4( \pm 13.8)$ & $83.7( \pm 13.2)$ & $82.5( \pm 13.3)$ & $<0.001$ \\
\hline Current-smokers (\%) & 45.6 & 33.1 & 38.1 & 46.8 & 65.9 & $<0.001$ \\
\hline $\begin{array}{l}\text { Physical inactivity (\%) } \\
\text { - Missing data (\%) }\end{array}$ & $\begin{array}{l}43.3 \\
12.3\end{array}$ & $\begin{array}{l}35.7 \\
18.6\end{array}$ & $\begin{array}{l}39.9 \\
15.3\end{array}$ & $\begin{array}{l}45.2 \\
10.1\end{array}$ & $\begin{array}{l}53.2 \\
4.4\end{array}$ & $<0.001$ \\
\hline Systolic BP (mmHg) & $123( \pm 16)$ & $120( \pm 14)$ & $122( \pm 15)$ & $124( \pm 17)$ & $126( \pm 18)$ & $<0.001$ \\
\hline Anti-hypertensive medication (\%) & 6.6 & 3.3 & 5.5 & 7.3 & 10.8 & $<0.001$ \\
\hline Cholesterol (mmol/L) & $5.66( \pm 1.09)$ & $5.36( \pm 1.01)$ & $5.56( \pm 1.05)$ & $5.77( \pm 1.08)$ & $5.99( \pm 1.11)$ & $<0.001$ \\
\hline History of CVD & 0.7 & 0.2 & 0.2 & 1.1 & 1.3 & $<0.001$ \\
\hline History of diabetes & 2.6 & 1.2 & 1.4 & 3.2 & 4.7 & $<0.001$ \\
\hline Social class (\%) & & & & & & - \\
\hline - Low skilled & 45.1 & 37.1 & 42.4 & 49.4 & 52.0 & \\
\hline - High skilled & 45.0 & 55.8 & 48.4 & 49.8 & 34.8 & \\
\hline - Self-employed & 2.9 & 2.8 & 2.8 & 2.8 & 3.1 & \\
\hline - Other & 7.1 & 4.2 & 6.3 & 8.1 & 10.1 & \\
\hline
\end{tabular}

Q Quartile, FEV 1 Forced expiratory volume in $1 \mathrm{~s}$, eGFR Estimated glomerular filtration rate, BMI Body mass index, BP Blood pressure, CVD Cardiovascular disease. Data consist of mean ( \pm standard deviation) unless otherwise stated. Linear by linear association for chi square tests used for $p$-value for categorical variables, ANOVA test for linearity used for $p$-values of continuous variables

relationship with future incident $\mathrm{CKD}$ events in men but not women, even after adjustment for confounding factors such as diabetes, smoking and BP.

\section{Comparison with existing literature}

The relationship between low lung function and various future health outcomes such as all-cause mortality [23], CVD [20, 24], CE [16, 17, 21] and even DM [5, 8, 9, 11, $36,37]$ and COPD [38, 39] has been explored in the past. The mechanisms linking some of these outcomes to low lung function have included chronic inflammation and hypoxia [30]; mechanisms that have also been thought to be linked to the development of CKD [30]. Our findings for incident CKD are consistent with the findings of the recent longitudinal study assessing low lung function at baseline and incident end-stage renal disease (ESRD) and CKD [30]. Although we did not assess ESRD, our findings for incident CKD events were found to be similar; low FVC was found to be a strong predictor of incident CKD. A restrictive lung profile had a stronger association with incident ESRD than an obstructive lung profile at baseline [30]. A population based study by Yoon et al. [26] also found the restrictive lung picture $(\mathrm{FVC}<80 \%)$ as opposed to an obstructive picture $\left(\mathrm{FEV}_{1} / \mathrm{VC}<0.70\right)$ to be associated with microalbuminuria. However, a recent retrospective cohort study in over 10,000 subjects from Korea [31] found that a $10 \%$ decrement in the $\mathrm{FEV}_{1} / \mathrm{FVC}$ ratio in non-smoking subjects was associated with a $35 \%$ increase in risk of future CKD after 5 years of follow-up. This is in contrast to our results (Supplement Tables 5 and 6). In our cohort of over 27,000 subjects, the $\mathrm{FEV}_{1} / \mathrm{FVC}$ ratio was not associated with incidence of CKD. This difference may exist due to the way CKD was defined as an outcome; in the retrospective study [31], a visit during follow-up for a health assessment was used to obtain eGFR measurements, which was then used to define the presence of CKD. In our prospective study design, subjects were followed up for extensive time periods and outcomes were ascertained as a first hospitalisation or outpatient visit due to CKD (or AKD which then led to CKD) with a diagnosis stated using ICD coding for CKD. Therefore, outcomes in our cohort may represent the more severe end of the disease spectrum, as subjects would need to have presented to secondary healthcare and been diagnosed by a health professional.

We have previously found that low $\mathrm{FEV}_{1}$ and FVC are strong predictors of DM in the MPP cohort [5]. In the study, again there was no link between an obstructive lung picture at baseline and future risk of DM. As DM is a risk factor for the development of CKD, DM could potentially mediate the relationship between lung function 
Table 3 Hazard ratios of incident CKD events by quartiles of $\mathrm{FEV}_{1}$ in men $(n=20,700)$

\begin{tabular}{|c|c|c|c|c|c|c|}
\hline & & $\begin{array}{l}\text { Q4 } \\
\text { (reference) }\end{array}$ & Q3 & Q2 & Q1 & $\begin{array}{l}\boldsymbol{P} \text { value for } \\
\text { trend }\end{array}$ \\
\hline & & $4.51( \pm 0.42)$ & $3.79( \pm 0.14)$ & $3.31( \pm 0.14)$ & $2.58( \pm 0.44)$ & \\
\hline Number (n) & 20,700 & 4813 & 5176 & 5388 & 5323 & - \\
\hline \multirow{3}{*}{$\begin{array}{l}\text { Incident CKD: } \\
\text { Main diagnosis } \\
(n=710)\end{array}$} & $\begin{array}{l}\text { CKD events } n \text { ( } n \text { per } 1000 \text { person- } \\
\text { years) }\end{array}$ & $130(0.82)$ & $167(1.00)$ & $191(1.16)$ & $222(1.52)$ & \\
\hline & Unadjusted & 1.00 & $1.26(1.00-1.58)$ & $\begin{array}{l}1.56(1.25- \\
1.95)\end{array}$ & $\begin{array}{l}2.40(1.93- \\
2.98)\end{array}$ & $<0.001$ \\
\hline & Adjusted $^{a}$ & 1.00 & $1.09(0.86-1.38)$ & $\begin{array}{l}1.19(0.94- \\
1.52)\end{array}$ & $\begin{array}{l}1.46(1.14- \\
1.89)\end{array}$ & 0.002 \\
\hline \multirow{3}{*}{$\begin{array}{l}\text { Incident CKD: } \\
\text { Main or secondary } \\
\text { diagnosis } \\
(n=1021)\end{array}$} & $\begin{array}{l}\text { CKD events } n \text { ( } n \text { per } 1000 \text { person- } \\
\text { years) }\end{array}$ & $183(1.15)$ & $241(1.45)$ & $287(1.74)$ & $310(2.13)$ & \\
\hline & Unadjusted & 1.00 & $1.29(1.06-1.56)$ & $\begin{array}{l}1.68(1.40- \\
2.02)\end{array}$ & $\begin{array}{l}2.41(2.01- \\
2.89)\end{array}$ & 0.000 \\
\hline & Adjusted $^{a}$ & 1.00 & $1.10(0.90-1.33)$ & $\begin{array}{l}1.24(1.02- \\
1.52)\end{array}$ & $\begin{array}{l}1.43(1.16- \\
1.77)\end{array}$ & $<0.001$ \\
\hline
\end{tabular}

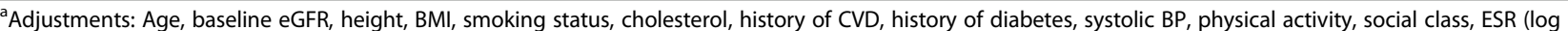
transformed), BP medication, screening year

Incident CKD events: includes both inpatient hospitalisations and outpatient diagnosis. Main diagnosis= Primary diagnosis, Main or secondary diagnosis = Primary diagnosis or 1 st-3rd secondary diagnosis

and CKD. However, the prevalence of DM was low in the MPP cohort and the risk of CKD was increased in men with low FVC or low $\mathrm{FEV}_{1}$, even after adjustment for prevalent $\mathrm{DM}$, which was defined by baseline fasting plasma glucose $\geq 7.0 \mathrm{mmol} / \mathrm{L}$, self-reported diabetes, questionnaire reporting DM medication or any prior diagnosis of DM recorded on relevant registers.

Lung function and CKD share common risk factors [31] such as, smoking, low birth weight, age, hypertension and obesity. The risk of CKD in relation to baseline $\mathrm{FEV}_{1}$ or FVC remained significant in men even after adjusting for smoking, age, systolic BP and BMI. The role of early life factors such as low birth weight however could not be explored, and could potentially explain some of the association between having reduced lung function and development of CKD in adult life.

Previously, an association has also been found between lung function decline on spirometry and future incident arterial hypertension [15, 40,41], which is a well-known important pathway in the pathogenesis of CKD. Another proposed mechanism that may link lung function to CKD is systemic inflammation. Those that have low levels of

Table 4 Hazard ratios of incident CKD events by quartiles of FEV 1 in women $(n=7325)$

\begin{tabular}{|c|c|c|c|c|c|c|}
\hline & & $\begin{array}{l}\text { Q4 } \\
\text { (reference) }\end{array}$ & Q3 & Q2 & Q1 & $\begin{array}{l}\boldsymbol{P} \text { value for } \\
\text { trend }\end{array}$ \\
\hline & & $3.31( \pm 0.33)$ & $2.80( \pm 0.08)$ & $2.46( \pm 0.11)$ & $1.88( \pm 0.33)$ & \\
\hline Number (n) & 7325 & 2027 & 1629 & 1933 & 1736 & - \\
\hline \multirow{3}{*}{$\begin{array}{l}\text { Incident CKD: } \\
\text { Main diagnosis } \\
(n=165)\end{array}$} & $\begin{array}{l}\text { CKD events } n \text { ( } n \text { per } 1000 \text { person- } \\
\text { years) }\end{array}$ & $29(0.44)$ & $36(0.70)$ & $51(0.89)$ & 49 (1.07) & \\
\hline & Unadjusted & 1.00 & $\begin{array}{l}1.64(1.01- \\
2.67)\end{array}$ & $\begin{array}{l}2.26(1.43- \\
3.57)\end{array}$ & $\begin{array}{l}3.15(1.99- \\
4.99)\end{array}$ & $<0.001$ \\
\hline & Adjusted $^{a}$ & 1.00 & $\begin{array}{l}1.21(0.73- \\
2.01)\end{array}$ & $\begin{array}{l}1.33(0.80- \\
2.20)\end{array}$ & $\begin{array}{l}1.27(0.73- \\
2.22)\end{array}$ & 0.403 \\
\hline \multirow{3}{*}{$\begin{array}{l}\text { Incident CKD: } \\
\text { Main or secondary } \\
\text { diagnosis } \\
(n=237)\end{array}$} & $\begin{array}{l}\text { CKD events } n \text { ( } n \text { per } 1000 \text { person- } \\
\text { years) }\end{array}$ & $40(0.61)$ & $52(1.01)$ & 75 (1.32) & $70(1.54)$ & \\
\hline & Unadjusted & 1.00 & $\begin{array}{l}1.73(1.14- \\
2.61)\end{array}$ & $\begin{array}{l}2.45(1.67- \\
3.60)\end{array}$ & $\begin{array}{l}3.38(2.29- \\
4.99)\end{array}$ & $<0.001$ \\
\hline & Adjusted $^{\mathrm{a}}$ & 1.00 & $\begin{array}{l}1.22(0.80- \\
1.87)\end{array}$ & $\begin{array}{l}1.31(0.86- \\
1.99)\end{array}$ & $\begin{array}{l}1.22(0.77- \\
1.94)\end{array}$ & 0.442 \\
\hline
\end{tabular}

\footnotetext{
adjustments: Age, baseline eGFR, height, BMI, smoking status, cholesterol, history of CVD, history of diabetes, systolic BP, physical activity, social class, ESR (log transformed), BP medication, screening year

Incident CKD events: includes both inpatient hospitalisations and outpatient diagnosis. Main diagnosis = Primary diagnosis, Main or secondary diagnosis = Primary diagnosis or 1st-3rd secondary diagnosis
} 


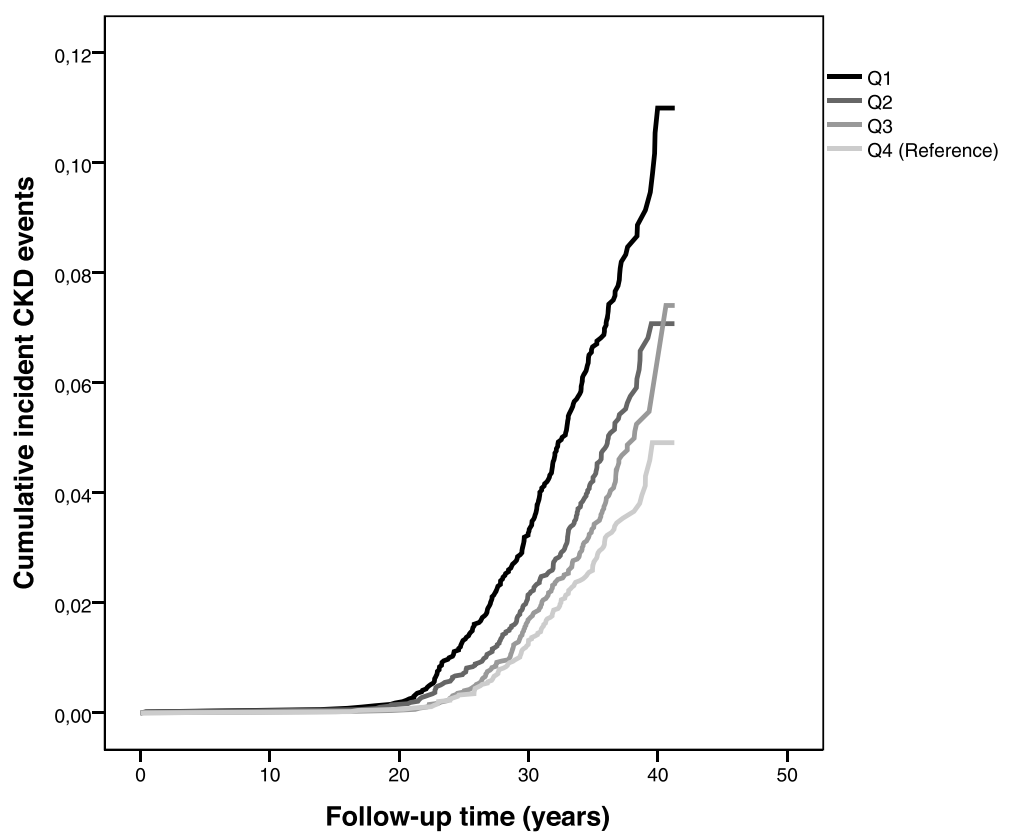

Fig. 1 Kaplan Meier curve of incident CKD events by quartiles of $\mathrm{FEV}_{1}(\mathrm{Q} 1$ : lowest lung function, Q4: highest lung function (reference) in men. Incident CKD events were main diagnosis on either inpatient or outpatient registers

lung function may exhibit underlying lung pathology associated with low-grade chronic inflammation. Persistent low grade inflammation is thought to be a "hall-mark feature" of CKD, where the role of inflammation in CKD progression and subsequent morbidity and mortality is well established [42]. Although we adjusted for ESR in our analysis and excluded those with a value of $\geq 50 \mathrm{~mm} / \mathrm{h}$ from the analysis, we did not adjust for various other inflammatory markers that could potentially play a role in the association between lung function and CKD. Therefore, we cannot fully exclude the potential effect of low-grade inflammation linking low levels of lung function to increased CKD risk.

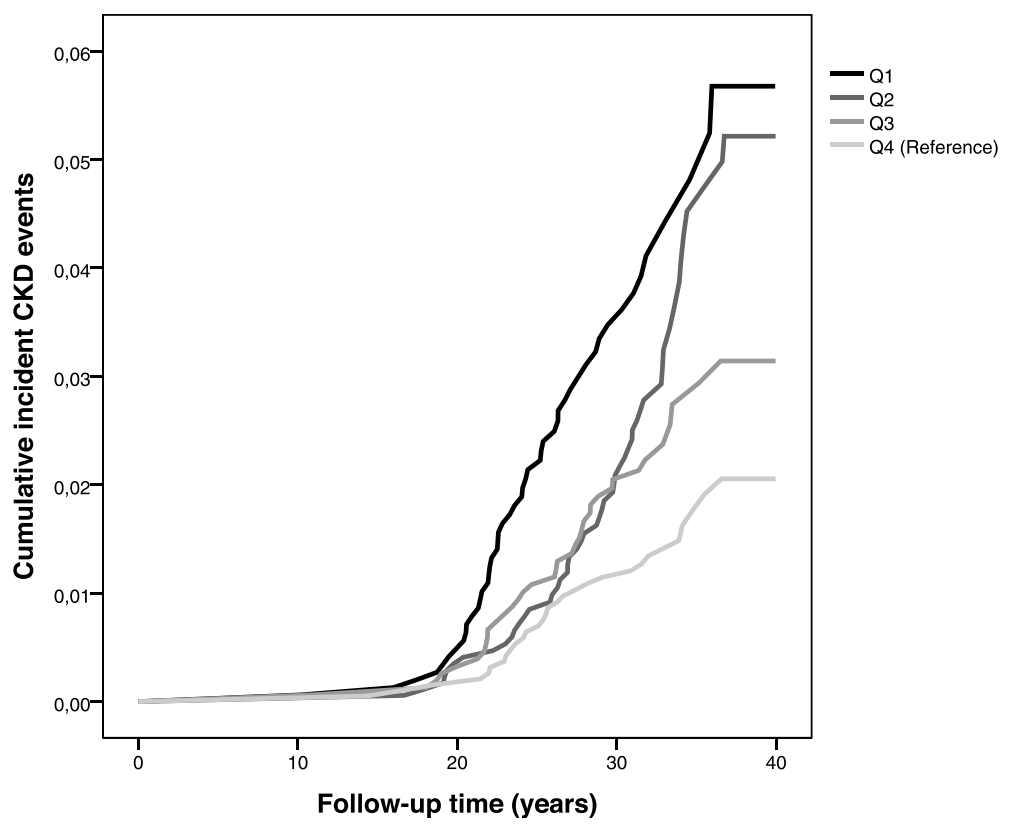

Fig. 2 Kaplan Meier curve of incident CKD events by quartiles of $\mathrm{FEV}_{1}(\mathrm{Q} 1$ : lowest lung function, Q4: highest lung function (reference) in women. Incident CKD events were main diagnosis on either inpatient or outpatient registers 
We found a significant relationship between low FEV 1 and incidence of CKD in men, but this relationship was non-significant after risk factor adjustment in women. The reason for this difference is unclear. As expected, incidence of CKD was higher in men than in women and since more men than women were included, the non-significant finding in women could be a result of lower statistical power. However, incidence of risk factors over a life span, such as diabetes and hypertension are also usually higher in men than in women. This could also possibly result in higher risks for men with poor lung function.

\section{Study limitations}

There are some methodological considerations for this study. The study was carried out before the current guidelines for spirometry were available. Therefore, no nose clips were used during spirometry measurements and only one acceptable manoeuvre was required, which could potentially have resulted in measurement errors. The long follow-up time for this study has its drawbacks along with its advantages. Many baseline characteristics may have changed over 41 years of follow-up. Interventions such as medication use for those with poorest lung function may have included corticosteroids which can potentially increase the risk of DM, in turn increasing the potential risk of diabetic nephropathy. However, it has been found that while this may be possible with oral corticosteroid use, inhaled corticosteroids such as budesonide are not associated with DM or hyperglycaemia in COPD or asthma patients treated with it [43]. Smoking rates have been known to have declined in Sweden [44], therefore it is very likely that many of the "baseline smokers" quit smoking during follow-up. However, this would if anything, bias our results towards the null. BMI also could have changed over this extensive follow-up period, which in turn could affect the risks of DM and hypertension, which are known risk factors for CKD. Individuals with hypertension, hyperglycemia, or hyperlipidemia were referred to an outpatient clinic for further risk factor evaluation and possible treatment. The beneficial effect of any intervention is however questionable. A study comparing the long term outcomes of the MPP (mortality and cardiovascular morbidity) found that risk factor screening for those who were invited to take part in the project did not result in a reduction in the total mortality [45].

The follow-up of CKD was based on national hospital based registers. One limitation is that cases that would have presented to primary care were missed. The outpatient register began in 2001, so additionally any CKD cases that would have also presented to outpatient care prior to this date would also have been missed.

In long-term follow-up studies, it is inevitable that creatinine is measured with methods not traceable to IDMS calibration, which was the case in our study. However, it was the same method throughout the study with stable reference values. No available data on urinary albumincreatinine ratio make it impossible for characterisation into CKD stages 1 and 2 at baseline. Therefore, CKD was defined as eGFR $<60 \mathrm{~mL} / \mathrm{min} / 1.73 \mathrm{~m}^{2}$ for exclusion at baseline as we had no information about albuminuria. However, even after widening the baseline exclusion criteria to eGFR $<70 \mathrm{~mL} / \mathrm{min} / 1.73 \mathrm{~m}^{2}$ (in order to overcome the potential issue of incomplete exclusion of prevalent CKD cases due to creatinine measurements not traceable to IDMS), we found the results remained largely unchanged. Therefore, we find it unlikely that the creatinine values used for the calculation of eGFR and baseline exclusions in our original analysis would have affected the results.

\section{Conclusion}

Low $\mathrm{FEV}_{1}$ and FVC values in early life are strongly associated with future incident CKD events in men even after adjustment for confounding factors such as diabetes, smoking and BP. Monitoring kidney function in those with reduced vital capacity in early life could help with identifying those at increased risk of future CKD. Lung function could therefore have a potential role in CKD risk prediction.

\section{Supplementary information}

Supplementary information accompanies this paper at https://doi.org/10. 1186/s12882-020-01758-0.

\section{Additional file 1: Table S1. Baseline characteristics in relation to quartiles of FVC: Males ( $n=20,700)$. Table S2. Baseline characteristics in relation to quartiles of FVC: Females $(n=7325)$. Table S3. Hazard ratios of incident CKD events by quartiles of FVC in men ( $n=20,700)$. Table S4. Hazard ratios of incident CKD events by quartiles of FVC in women ( $n=7325)$. Table S5. Hazard ratios of incident CKD events by FEV 1 NC ratio in men $(n=20,700)$. Table $\mathbf{S 6}$. Hazard ratios of incident CKD events by $\mathrm{FEV}_{1} \mathrm{NC}$ ratio in women $(n=7325)$.}

\begin{abstract}
Abbreviations
CKD: Chronic kidney disease; CVD: Cardiovascular disease; DM: Diabetes mellitus; CE: Coronary events; MPP: Malmö Preventive Project;

eGFR: Estimated glomerular filtration rate; FVC: Forced vital capacity; $\mathrm{FEV}_{1}$ : Forced expiratory volume in $1 \mathrm{~s}$; ESR: Erythrocyte sedimentation rate; IDMS: Isotope dilution mass spectrometry; SEl: Statistics Sweden socioeconomic index; ICD: International classification of diseases; AKD: Acute kidney disease; ANOVA: One-way analysis of variance; BMl: Body mass index; Q: Quartile; BP: Blood pressure; HR: Hazard ratio; COPD: Chronic obstructive pulmonary disease; ESRD: End-stage renal disease
\end{abstract}

\section{Acknowledgements}

Not applicable.

Authors' contributions

SZ, AC, PW and GE participated in study design, interpretation of data, drafting the manuscript and approved the final version of the manuscript. SZ performed the statistical analyses and prepared the first draft of the manuscript. All authors take responsibility for the integrity and accuracy of the work. The authors read and approved the final manuscript. 


\section{Funding}

This study was supported by the Swedish Heart-Lung foundation [2016-0315]. The funding body had no role in the study design or interpretation of the results. Open access funding provided by Lund University.

\section{Availability of data and materials}

The MPP steering committee coordinates research using the MPP database The data base is open for applications for research projects. Contact: Anders Dahlin, PhD, data manager, Email: Anders.Dahlin@med.lu.se

\section{Ethics approval and consent to participate}

The Health Service Authority of Malmö approved and funded the screening program. The linkage with the cause of death and patient registers was approved by the Regional ethics committee at Lund University. LU 2004-85; Written consent was not available at the time the study was conducted, however verbal consent was taken for all participants included in the study. Advertisements in newspapers were later published to inform about the studies and give participants the possibility to opt-out. The procedures were approved by the regional ethics committee at Lund university (2004-85).

\section{Consent for publication}

Not applicable.

\section{Competing interests}

PW reports grants from Swedish Heart and Lung Foundation during the conduct of the study; personal fees from AstraZeneca, personal fees from Chiesi Pharma outside the submitted work. In addition, PW has a patent Device and method for pulmonary function measurement issued. SZ, AC and GE have no competing interests to disclose.

\section{Author details}

'Department of Clinical Sciences Malmö, Lund University, CRC 60:13, Jan Waldenströms gata 35, S-20502 Malmö, Sweden. ${ }^{2}$ Department of Nephrology, Skåne University Hospital, Malmö, Sweden. ${ }^{3}$ Department of Translational Medicine, Lund University, Malmö, Sweden.

\section{Received: 9 October 2019 Accepted: 5 March 2020}

\section{1.}

\section{References}

1. Eckardt KU, Coresh J, Devuyst O, Johnson RJ, Kottgen A, Levey AS, et al. Evolving importance of kidney disease: from subspecialty to global health burden. Lancet (London, England). 2013;382(9887):158-69.

2. Haroun MK, Jaar BG, Hoffman SC, Comstock GW, Klag MJ, Coresh J. Risk factors for chronic kidney disease: a prospective study of 23,534 men and women in Washington County, Maryland. J Am Soc Nephrol. 2003;14(11): 2934-41.

3. Levin A. Identification of patients and risk factors in chronic kidney diseaseevaluating risk factors and therapeutic strategies. Nephrol Dial Transplant. 2001;16(Suppl 7):57-60.

4. Kazancioğlu R. Risk factors for chronic kidney disease: an update. Kidney Int Suppl. 2013;3(4):368-71.

5. Zaigham S, Nilsson PM, Wollmer P, Engstrom G. The temporal relationship between poor lung function and the risk of diabetes. BMC Pulm Med. 2016; 16(1):75

6. Barker DJ, Godfrey KM, Fall C, Osmond C, Winter PD, Shaheen SO. Relation of birth weight and childhood respiratory infection to adult lung function and death from chronic obstructive airways disease. BMJ. 1991;303(6804): $671-5$.

7. Walter RE, Beiser A, Givelber RJ, O'Connor GT, Gottlieb DJ. Association between glycemic state and lung function: the Framingham heart study. Am J Respir Crit Care Med. 2003;167(6):911-6.

8. Yeh HC, Punjabi NM, Wang NY, Pankow JS, Duncan BB, Cox CE, et al. Crosssectional and prospective study of lung function in adults with type 2 diabetes: the atherosclerosis risk in communities (ARIC) study. Diabetes Care. 2008:31(4):741-6.

9. Yeh HC, Punjabi NM, Wang NY, Pankow JS, Duncan BB, Brancati FL. Vital capacity as a predictor of incident type 2 diabetes: the atherosclerosis risk in communities study. Diabetes Care. 2005;28(6):1472-9.
10. Lazarus R, Sparrow D, Weiss ST. Baseline ventilatory function predicts the development of higher levels of fasting insulin and fasting insulin resistance index: the normative aging study. Eur Respir J. 1998;12(3):641-5.

11. Engstrom G, Janzon L. Risk of developing diabetes is inversely related to lung function: a population-based cohort study. Diabet Med. 2002;19(2): 167-70.

12. Kwon CH, Rhee EJ, Song JU, Kim JT, Kwag HJ, Sung KC. Reduced lung function is independently associated with increased risk of type 2 diabetes in Korean men. Cardiovasc Diabetol. 2012;11:38.

13. Ford ES, Mannino DM. Prospective association between lung function and the incidence of diabetes: findings from the National Health and nutrition examination survey epidemiologic follow-up study. Diabetes Care. 2004; 27(12):2966-70.

14. Wannamethee SG, Shaper AG, Rumley A, Sattar N, Whincup PH, Thomas $M C$, et al. Lung function and risk of type 2 diabetes and fatal and nonfatal major coronary heart disease events: possible associations with inflammation. Diabetes Care. 2010;33(9):1990-6.

15. Jacobs DR Jr, Yatsuya H, Hearst MO, Thyagarajan B, Kalhan R, Rosenberg S, et al. Rate of decline of forced vital capacity predicts future arterial hypertension: the Coronary Artery Risk Development in Young Adults Study. Hypertension (Dallas, Tex : 1979). 2012;59(2):219-25.

16. Friedman $G D$, Klatsky $A L$, Siegelaub $A B$. Lung function and risk of myocardial infarction and sudden cardiac death. N Engl J Med. 1976; 294(20):1071-5.

17. Schroeder EB, Welch VL, Couper D, Nieto FJ, Liao D, Rosamond WD, et al. Lung function and incident coronary heart disease: the atherosclerosis risk in communities study. Am J Epidemiol. 2003;158(12):1171-81.

18. Lange P, Nyboe J, Jensen G, Schnohr P, Appleyard M. Ventilatory function impairment and risk of cardiovascular death and of fatal or non-fatal myocardial infarction. Eur Respir J. 1991:4(9):1080-7.

19. Engstrom G, Hedblad B, Janzon L. Reduced lung function predicts increased fatality in future cardiac events. A population-based study. J Intern Med. 2006;260(6):560-7.

20. Sin DD, Wu L, Man SF. The relationship between reduced lung function and cardiovascular mortality: a population-based study and a systematic review of the literature. Chest. 2005;127(6):1952-9.

21. Mattila T, Vasankari T, Rissanen $H$, Knekt P, Puukka P, Heliovaara M. Airway obstruction and the risk of myocardial infarction and death from coronary heart disease: a national health examination survey with a 33-year follow-up period. Eur J Epidemiol. 2018;33(1):89-98.

22. Lee HM, Liu MA, Barrett-Connor $E$, Wong ND. Association of lung function with coronary heart disease and cardiovascular disease outcomes in elderly: the rancho Bernardo study. Respir Med. 2014;108(12):1779-85.

23. Young RP, Hopkins R, Eaton TE. Forced expiratory volume in one second: not just a lung function test but a marker of premature death from all causes. Eur Respir J. 2007;30(4):616-22.

24. Kannel WB, Hubert $H$, Lew EA. Vital capacity as a predictor of cardiovascular disease: the Framingham study. Am Heart J. 1983;105(2):311-5.

25. Incalzi RA, Corsonello A, Pedone C, Battaglia S, Paglino G, Bellia V. Chronic renal failure: a neglected comorbidity of COPD. Chest. 2010; 137(4):831-7.

26. Yoon JH, Won JU, Ahn YS, Roh J. Poor lung function has inverse relationship with microalbuminuria, an early surrogate marker of kidney damage and atherosclerosis: the 5th Korea National Health and nutrition examination survey. PLoS One. 2014;9(4):e94125.

27. Casanova C, de Torres JP, Navarro J, Aguirre-Jaime A, Toledo P, Cordoba E, et al. Microalbuminuria and hypoxemia in patients with chronic obstructive pulmonary disease. Am J Respir Crit Care Med. 2010;182(8):1004-10.

28. Bulcun E, Ekici M, Ekici A, Kisa U. Microalbuminuria in chronic obstructive pulmonary disease. Copd. 2013;10(2):186-92.

29. Mukai H, Ming P, Lindholm B, Heimburger O, Barany P, Anderstam B, et al. Restrictive lung disorder is common in patients with kidney failure and associates with protein-energy wasting, inflammation and cardiovascular disease. PLoS One. 2018;13(4):e0195585

30. Sumida K, Kwak L, Grams ME, Yamagata K, Punjabi NM, Kovesdy CP, et al. Lung function and incident kidney disease: the atherosclerosis risk in communities (ARIC) study. Am J Kidney Dis. 2017:70(5):675-85.

31. Kim SK, Bae JC, Baek JH, Hur KY, Lee MK, Kim JH. Is decreased lung function associated with chronic kidney disease? A retrospective cohort study in Korea. BMJ Open. 2018;8(4):e018928. 
32. KDIGO. Clinical practice guideline for the evaluation and management of chronic kidney disease. Kidney Int Suppl. 2012;2013:19-62.

33. Levey AS, Stevens LA, Schmid CH, Zhang YL, Castro AF 3rd, Feldman HI, et al. A new equation to estimate glomerular filtration rate. Ann Intern Med. 2009;150(9):604-12.

34. Levin A, Stevens PE, Bilous RW, Coresh J, De Francisco ALM, De Jong PE, et al. Kidney disease: improving global outcomes (KDIGO) CKD work group. KDIGO 2012 clinical practice guideline for the evaluation and management of chronic kidney disease. Kidney Int Suppl. 2013;3(1):1-150.

35. Bao X, Borné Y, Muhammad IF, Schulz C-A, Persson M, Orho-Melander M, et al. Complement C3 and incident hospitalization due to chronic kidney disease: a population-based cohort study. BMC Nephrol. 2019;20(1):61.

36. Davis TM, Knuiman M, Kendall P, Vu H, Davis WA. Reduced pulmonary function and its associations in type 2 diabetes: the Fremantle diabetes study. Diabetes Res Clin Pract. 2000;50(2):153-9.

37. Litonjua AA, Lazarus R, Sparrow D, Demolles D, Weiss ST. Lung function in type 2 diabetes: the normative aging study. Respir Med. 2005;99(12):158390.

38. Zaigham $S$, Wollmer P, Engstrom G. Lung function, forced expiratory volume in $1 \mathrm{~s}$ decline and COPD hospitalisations over 44 years of follow-up. Eur Respir J. 2016;47(3):742-50.

39. Mannino DM, Sonia Buist A, Vollmer WM. Chronic obstructive pulmonary disease in the older adult: what defines abnormal lung function? Thorax. 2007;62(3):237-41.

40. Engstrom G, Wollmer P, Valind S, Hedblad B, Janzon L. Blood pressure increase between 55 and 68 years of age is inversely related to lung function: longitudinal results from the cohort study 'Men born in 1914'. J Hypertens. 2001;19(7):1203-8.

41. Sparrow D, Weiss ST, Vokonas PS, Cupples LA, Ekerdt DJ, Colton T. Forced vital capacity and the risk of hypertension. The normative aging study. Am J Epidemiol. 1988;127(4):734-41.

42. Mihai S, Codrici E, Popescu ID, Enciu AM, Albulescu L, Necula LG, et al. Inflammation-related mechanisms in chronic kidney disease prediction, progression, and outcome. J Immunol Res. 2018;2018:2180373.

43. O'Byrne PM, Rennard S, Gerstein H, Radner F, Peterson S, Lindberg B, et al. Risk of new onset diabetes mellitus in patients with asthma or COPD taking inhaled corticosteroids. Respir Med. 2012;106(11):1487-93.

44. Midlov P, Calling S, Sundquist J, Sundquist K, Johansson SE. The longitudinal age and birth cohort trends of smoking in Sweden: a 24-year follow-up study. Int J Public Health. 2014;59(2):243-50.

45. Berglund G, Nilsson P, Eriksson KF, Nilsson JA, Hedblad B, Kristenson H, et al. Long-term outcome of the Malmo preventive project: mortality and cardiovascular morbidity. J Intern Med. 2000;247(1):19-29.

\section{Publisher's Note}

Springer Nature remains neutral with regard to jurisdictional claims in published maps and institutional affiliations.

Ready to submit your research? Choose BMC and benefit from:

- fast, convenient online submission

- thorough peer review by experienced researchers in your field

- rapid publication on acceptance

- support for research data, including large and complex data types

- gold Open Access which fosters wider collaboration and increased citations

- maximum visibility for your research: over $100 \mathrm{M}$ website views per year

At $\mathrm{BMC}$, research is always in progress.

Learn more biomedcentral.com/submissions 